\title{
A New Approach to Model the Effect of Climate Change on the Building Sector: a Climate
} Models Data Fusion

\author{
Giovanni Tumminia ${ }^{1}$, Francesco Guarino ${ }^{1}$, Daniele Croce $^{1}$, Sonia Longo ${ }^{1}$, Ilenia Tinnirello ${ }^{1}$, Marco \\ Ferraro $^{2}$, Marina Mistretta ${ }^{3}$, Maurizio Cellura ${ }^{1}$ \\ ${ }^{1}$ University of Palermo, Palermo, Italy \\ ${ }^{2}$ Institute for Advanced Energy Techonologies "Nicola Giordano" - National Research Council of \\ Italy, Messina, Italy \\ ${ }^{3}$ University of Reggio Calabria, Reggio Calabria, Italy
}

\begin{abstract}
Several climate models have been developed and used to forecast the effects of the climate changes, however the variability of results due to different models lead to a significant uncertainty on the estimation of the building energy use for the next century. In this context, the paper analyses this uncertainty and combines different climate models in order to improve the robustness of energy consumption predictions. The data of the climate models were then used to generate hourly weather files for the future period 2020-2099 and energy simulations for a case study located in Palermo (Italy) were performed. Results show a wide variability among all models (either alone or combined with our data-fusion method), with a mean variability of about $18 \%$ of the cooling energy requirements considering the RCP4.5 scenario. This reinforces the need for a more detailed validation and alternative climate change models for building simulation.
\end{abstract}

\section{Introduction}

Climate change is widely acknowledged as a primary environmental problem. In this context, while the technologies to reach a low-carbon building sector already exist (Beccali et al., 2012; Beccali, Cellura, Longo, \& Guarino, 2016; Bobba et al., 2018; S Ferrari \& Zagarella, 2015; Tumminia et al., 2018), the potential impact of climate change to the building sector is so large that trying to identify future trends and pathways towards decarbonisation is fundamental for a sustainable future (Maurizio Cellura, Guarino, Longo, \& Mistretta, 2017; Finocchiaro, Beccali, Cellura, Guarino, \& Longo, 2016).

In particular, since the long lifetime of buildings corresponds to the timescale over which the climate is expected to show substantial change, the buildings constructed today need to be resilient to future climates (Beccali, Cellura, \& Mistretta, 2007; Guan, 2012; Hamdy, Carlucci, Hoes, \& Hensen, 2017). Moreover, climate change could cause worsening of current issues of high performance buildings such as overheating even in nontraditionally cooling dominated countries, coupled with a large increase in power generation needs for cooling (M Cellura et al., 2011; Simone Ferrari \& Zanotto, 2012; Robert \& Kummert, 2012; Zhai \& Helman, 2019).
Predicting future climatic conditions is the starting point to all building climate change impact studies. In this context, different General Circulation Models (GCMs) were developed to obtain predictions of the future climate. GCMs are essentially mathematical models of the general circulation of a planetary atmosphere, which describe the most important components, processes and interactions in the climate system. The GCMs predict climate at a relatively high level of spatial and temporal resolution (typical spatial resolution of $150-600 \mathrm{~km}$ (Taylor, Stouffer, \& Meehl, 2012)). During the past two decades, GCMs were downscaled to regional climate models (RCMs) by making use of a nesting strategy to obtain climate information at a resolution of 10-100 km (Stocker D. et al., 2013). However, driven by the fact that assessing the impact of climate change on building performance requires local weather data at higher temporal resolution, the GCM or RCM outputs have to be "downscaled", referring to a process of generating climate change information at spatial and temporal scales lower than those provided by these models.

To adapt GCMs or RCMs outputs and assess the impact of climate change on building performance two different approaches can be usually found in the state of the art: statistical methods and building simulation approaches. Statistical methods were used to model the interactions between the local meteorological variables and the building energy demand based on historical available data. An example is the prediction of building energy consumption using the degree-days approach (Artmann, Gyalistras, Manz, \& Heiselberg, 2008; H. Wang \& Chen, 2014). It is essentially a steady-state approach aimed at the quantification of building energy use for heating and cooling. This approach is not particularly effective in the context of energy use prediction via detailed dynamic building simulation, as having availability of hourly future weather data is a prerequisite and a key point for the energy demand prediction by taking advantage of building simulation tools (Gupta \& Gregg, 2012). In this context, the creation of future weather files is usually approached by a mathematical transformation (morphing) (Belcher, Hacker, \& Powell, 2005) of the time series of existing current weather files using climate change forecasts produced by GCMs or RCMs. 
Through the Fifth Assessment Report, the Intergovernmental Panel on Climate Change (IPCC) has recommended 58 different GCMs, developed by 23 different research centres, based on the latest 4 IPCC emissions scenarios, called Representative Concentration Pathways (RCP2.6, RCP4.5, RCP6.0 and RCP8.5) (Taylor et al., 2012). RCPs describe four different $21^{\text {st }}$ century pathways of greenhouse gas (GHG) emissions and atmospheric concentrations over time, air pollution and land use. These scenarios include a stringent mitigation scenario (RCP2.6), two intermediate scenarios (RCP4.5 and RCP6.0), and one scenario with very high GHG emissions (RCP8.5) (Allen et al., 2014). However, even though all models can predict the same climate change scenarios, each model delivers significantly different outputs. Assumptions and other model differences produce distinct projections even for the same scenario. In this context, limited efforts have been performed in the building sector towards a comparative analysis of the climate change models used in the last IPCC report to choose and combine the more relevant ones in a new model that better fit the historical data.

In this framework, the paper proposes the analysis of different GCMs based forecasts of climate change. These data are compared with an existing climate database to compare simulated with historical weather data, aimed at generating a new 'data-fusion' dataset through the combination of different IPCC GCMs in order to achieve a new more robust dataset if compared to the real available data to be used for building simulation.

\section{Methods}

As shown in Figure 1, the methodological steps followed during the work are recapped below:

- Models data fusion: using a multiple linear regression method, four different GCMs are combined into one model (data fusion model) so that the trend of the historical data of the generated model is similar to the data of an historical weather database (ERA-Interim Database);

- Future hourly weather data: the data fusion model and also of the four single models are used to construct future climate weather data files for period 2020-2099 using 2 RCP emission scenarios (RCP4.5 and RCP8.5) through the morphing method;

- Building simulation: a case study is modelled in EnergyPlus enviroment in order to assess the effect of the climate change on the building energy use for heating and cooling for the city of Palermo, Italy.

\section{Models Data Fusion}

Each GCM includes different types of simulations, such as historical and future projections forced by RCP scenarios. Historical simulations cover much of the industrial period and are guided by the changes observed in the atmospheric composition (both of anthropogenic nature and of natural origin) and by the time-evolving land cover. For future projections, the RCP 4.5 and RCP8.5 scenarios were considered as examples. In particular, RCP 8.5 is a business as usual scenario, with no policy changes to reduce emissions (three times today's $\mathrm{CO}_{2}$ emissions by 2100) while RCP4.5 is representative of a "midrange mitigation emission" scenario, where greenhouse gas emissions peak around 2040 and afterwards decline.

In particular, the GCMs showed in Table 1 were used, in a specific location (latitude $38.75^{\circ}$, longitude $13.25^{\circ}$ ) for the following parameters:

- $\quad$ Tas (Near-Surface Air Temperature [K]);

- $\quad$ sfcWind (wind speed $[\mathrm{m} / \mathrm{s}]$ );

- Rsds (Surface Downwelling Shortwave Radiation $\left.\left[\mathrm{W} / \mathrm{m}^{2}\right]\right)$.

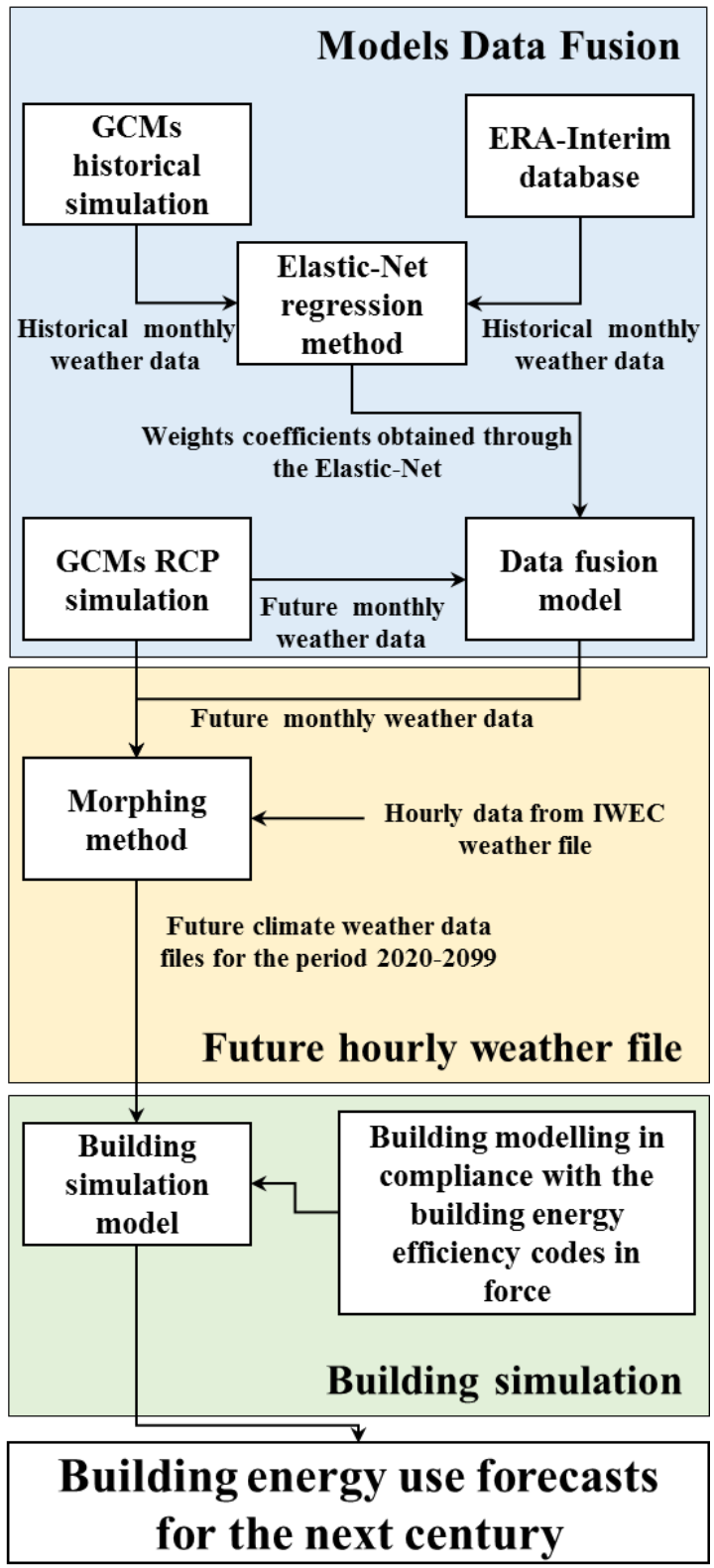

Figure 1: Sketch of the methodological framework.

Among all the GCMs recommended by the IPPC in the context of the Fifth Assessment Report, these models were selected because have the same horizontal grid resolution (latitude: $1.25^{\circ}$, longitude: $1.875^{\circ}$ ), avoiding the need to remap different models to the same spatial grid. Although the proposed methodology could be easily 
applied to any set of climatic data, this allows to remove one layer of uncertainty from the results as all data used in this paper use the same spatial grid, removing the need for further manipulation of the data to achieve comparable inputs.

Since these climate variables are characterized by a strong seasonal component which deeply influences the time series, each weather parameter of the GCMs historical simulation was decomposed into a seasonal component, a linear trend and random residual component. Then, for combining the models, each trace was compared with historical weather data provided by the ERA-Interim dataset, in terms of linear trends and variance of the residuals (rather than comparing the sum of errors produced by the temporal traces).

Table 1: Selected GCMs.

\begin{tabular}{|c|c|}
\hline GCM & Research centre \\
\hline ACCESS 1.0 & \multirow{2}{*}{$\begin{array}{c}\text { Commonwealth Scientific and Industrial } \\
\text { Research Organization/Bureau of } \\
\text { Meteorology Australia }\end{array}$} \\
\hline ACCESS1.3 & \\
\hline HadGEM2-AO & $\begin{array}{l}\text { National Institute of Meteorological } \\
\text { Research, Korea Meteorological } \\
\text { Administration, South Korea }\end{array}$ \\
\hline HadGEM2-CC & Met Office Hadley Centre, UK \\
\hline
\end{tabular}

In detail, ERA-Interim is the last global atmospheric database produced by the European Centre for MediumRange Weather Forecasts covering the period since 1 January 1979 onwards. It was selected as reference data source because it is an official validation dataset used for the comparison of GCMs (Bojanowski, Vrieling, \& Skidmore, 2014; Brands, Herrera, Fernández, \& Gutiérrez, 2013; Carvalho, Rocha, Gómez-Gesteira, \& Silva Santos, 2017).

To combine the different models into one single model, a multiple linear regression method was used. It is a machine learning technique that "weights" each dataset according to the climatic input data without introducing any additional hypothesis.

In detail, in the linear regression method the output is equal to the sum of a weighted combination of the input, as shown in equation (1).

$$
y(w, X)=w_{1} x_{1}+\cdots+w_{p} x_{p}
$$

where the vector $\mathrm{w}=\left(\mathrm{w}_{1}, \ldots, \mathrm{w}_{\mathrm{p}}\right)$ contains the coefficients (regression weights) of the inputs $\mathrm{X}=\left(\mathrm{x}_{1}, \ldots, \mathrm{x}_{\mathrm{p}}\right)$, while $\mathrm{y}$ is the output linear combination.

The regression weights were selected in order to minimize the difference between the output linear combination $y$ and the historical data from the ERA-Interim database (Dee et al., 2011). The obtained regression weights allow to combine linearly the four selected GCMs and obtain a unified model, spanning the same time period, for each climatic parameter considered. The regression weights have been obtained using historical data from years 19792000 that overlap on the ERA-Interim period, for the climate parameters tas, sfcWind and rsds, in the Palermo, Italy area (Latitude $38.75^{\circ}$, Longitude $13.125^{\circ}$ ).
In order to obtain the regression weights, a simple solution is to use the Least Square Error method that minimizes the MSE (Mean Square Error), or the standardized version of the MSE, namely the coefficient of determination $\mathrm{R}^{2}$.

This approach, although valid in many cases, is based on the assumption that the different inputs of the model are independent. However, when the inputs are correlated and the columns of the $\mathrm{X}$ matrix have a quasi-linear dependence (as in this case), the method becomes highly sensitive to the random fluctuations of the response, producing a large variance that makes the values of the coefficients w not reliable.

To overcome this problem, the Elastic-Net regression method was used (Zou \& Hastie, 2005). It is a more sophisticated linear regression model trained with two regularization parameters, $\alpha$ e $\rho$. Its objective function to be minimized can be expressed mathematically in the following form:

$$
\min _{w} \frac{1}{2 n_{\text {samples }}}\|X w-y\|_{2}^{2}+\alpha \rho\|w\|_{1}+\frac{\alpha(1-\rho)}{2}\|w\|_{2}^{2}
$$

The combined action of $\alpha$ and $\rho$ keeps the amplitude of the coefficients low and at the same time tries to guarantee a certain "sparsity" of the coefficients. The appropriate choice of these parameters is a useful way to reduce the risk of overfitting.

The regularization parameters $\alpha$ and $\rho$ were identified through the cross-validation mechanism with grid search using the ElasticNetCV classifier of the scikit-learn Python library for machine learning (Pedregosa et al., 2011). More detailed information on how we implement and use the ElasticNetCV regression can be found in $(\mathrm{F}$. Guarino, Inzerillo, Croce, Tinnirello \& Cellura, 2018) Tables 2 and 3 show the regularization parameters and the regression weights obtained, respectively.

Table 2: Regularization parameters obtained for the three parameters of interest.

\begin{tabular}{|l|c|c|}
\hline & $\boldsymbol{\alpha}$ & $\boldsymbol{\rho}$ \\
\hline Tas & 10 & 0.001 \\
\hline SfcWind & 0.001 & 0.75 \\
\hline RSDS & 10 & 0.5 \\
\hline
\end{tabular}

Table 3: Regression weights obtained through the Elastic-Net.

\begin{tabular}{|l|c|c|c|c|}
\hline & $\mathbf{w}_{\mathbf{1}}$ & $\mathbf{w}_{\mathbf{2}}$ & $\mathbf{w} \mathbf{3}$ & $\mathbf{w} \mathbf{4}$ \\
\hline Tas & 0.386 & 0.371 & 0.182 & 0.061 \\
\hline SfcWind & 0.153 & 0.477 & 0.122 & 0.173 \\
\hline RSDS & 0.422 & 0.139 & 0.408 & 0.055 \\
\hline
\end{tabular}

Table 4 shows the MSE and $\mathrm{R}^{2}$ coefficient for the resulting data fusion model and of the four single models compared to the ERA-Interim dataset. In detail, for all the climatic variables considered, the data fusion model shows a higher $\mathrm{R}^{2}$ coefficient and a lower MSE if compared to the individual GCMs, resulting in a model that better fit historical data of ERA-Interim database.

Finally, the weights coefficients obtained on the historical datasets through the Elastic-Net method were used to 
obtain a unified future forecast model based on the RCP4.5 and RCP8.5 scenarios.

Table 4: MSE and $R^{2}$ coefficient of selected GCMs compared to the ERA Interim dataset.

\begin{tabular}{|c|c|c|c|c|c|c|}
\hline & \multicolumn{2}{|c|}{ Tas $[\mathbf{K}]$} & \multicolumn{2}{|c|}{$\begin{array}{c}\text { SfcWind } \\
{[\mathrm{m} / \mathrm{s}]}\end{array}$} & \multicolumn{2}{|c|}{$\operatorname{Rsds}\left[\mathbf{W} / \mathbf{m}^{2}\right]$} \\
\hline & MSE & $\mathbf{R}^{2}$ & MSE & $\mathbf{R}^{2}$ & MSE & $\mathbf{R}^{2}$ \\
\hline ACCESS1.0 & 3.14 & 0.87 & 1.05 & 0.44 & 310.68 & 0.96 \\
\hline ACCESS1.3 & 2.67 & 0.89 & 1.47 & 0.21 & 411.42 & 0.94 \\
\hline HadGEM2-AO & 2.32 & 0.90 & 1.56 & 0.17 & 367.39 & 0.95 \\
\hline HadGEM2-CC & 3.20 & 0.87 & 1.89 & -0.01 & 359.08 & 0.95 \\
\hline Data fusion model & 2.17 & 0.91 & 0.72 & 0.62 & 262.78 & 0.96 \\
\hline
\end{tabular}

\section{Future hourly weather data}

The results achieved from the previous step were used for development of weather data files to be used for simulation of future energy performances in a non-steady state simulation environment.

Both the original climate data from the 4 GCMs and the data-fusion results were used for the generation of hourly weather data file for the period 2020-2090 through the application of the "morphing method" proposed by (Belcher et al., 2005) allowing to modify a hourly weather data for the desired site on the basis of forecasted factors and disturbances to climate.

The morphing method (Belcher et al., 2005) is based on three operations, which can be described as: shift (equation (3)); linear stretch (equation (4)); shift and stretch (equation (5)).

$$
\begin{gathered}
z=z_{0}+\Delta z_{m} \\
z=\alpha_{m} z_{0} \\
z=z_{0}+\Delta z_{m}+\alpha_{m}\left(z_{0}-\left\langle z_{0}\right\rangle\right.
\end{gathered}
$$

where the subscripts " 0 " identify current weather variables, while the subscripts "m" identify monthly future whether data. In detail, $\mathrm{z}$ is a future hourly climate variable, $\mathrm{z}_{0}$ is the hourly value of the current climate variable, $\Delta z_{m}$ and $\alpha_{m}$ are the absolute variation and the percentage variation of said climate variable due to climate change for month $\mathrm{m}$, respectively, and $\left\langle\mathrm{z}_{0}\right\rangle$ is the monthly mean of the variable $\mathrm{z}_{0}$.

This method was used because it is one of the most used in researches on the impact of climate change on building energy use in the U.S.A ((L. Wang, Liu, \& Brown, 2017), in Canada (Robert \& Kummert, 2012), in Australia (Ren, Chen, \& Wang, 2011), in Asia (Song \& Ye, 2017) and in Europe (Maurizio Cellura, Guarino, Longo, \& Tumminia, 2018) using as input different GCMs, climate change scenarios and future time slices.

The IWEC (International Weather for Energy Calculation) EPW weather file format (Thevenard \& Brunger, 2002) for the city of Palermo was selected as the baseline weather data in input to the morphing method because it is one of the most widely weather formats used by energy building simulation tools.

\section{Building simulation}

An ideal building model was modelled in EnergyPlus environment (DoE, 2010). The building performances have been analysed with a sub-hourly detail (10 min time step) by using the conduction transfer function method for the envelope and the heat balance method to analyse the thermal zones.

As shown in Figure 2, a multi-storey building model was used as ideal case study with a total heated area of $400 \mathrm{~m}^{2}$. An isolated building was chosen to adopt the worst conditions for cooling since climate change will most likely increase this typology of energy use in the future ( $S$ Ferrari \& Zanotto, 2016).

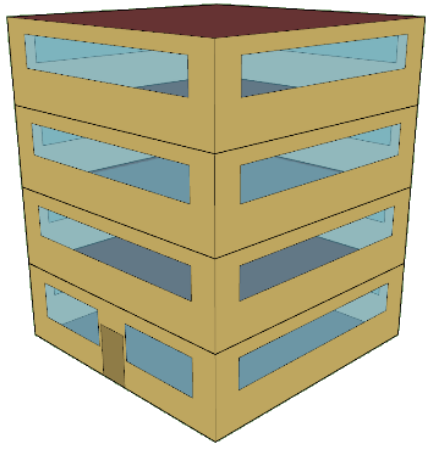

Figure 2: The building model used as case study.

The building is an office occupied from Monday to Friday from 9:00 a.m. until 6:00 p.m., with a break for lunch from 1:00 p.m. to 2:00 p.m. Table 5 reports the main buildings features. In particular, the window-to-wall ratio of all façades is about $30 \%$, with about $36 \mathrm{~m}^{2}$ of glazed area (Goia, 2016).

Table 5: Building features.

\begin{tabular}{|l|l|}
\hline Heated Floor area $\left[\mathrm{m}^{2}\right]$ & 400 \\
\hline Volume $\left[\mathrm{m}^{3}\right]$ & 1,200 \\
\hline S/V overall ratio $\left[\mathrm{m}^{-1}\right]$ & 0.48 \\
\hline Window to wall ratio [\%] & 30 \\
\hline
\end{tabular}

Since the typical lifetime of buildings is in the range of 50-100 years and in order to ensure representativeness of the building modelled, the building envelope features are chosen in compliance with the minimum requirements for a new non-residential building in force for the city examined, Palermo (Italy) (Ministero dello Sviluppo Economico, 2015).

The windows are made of a double panel insulated glazing, the average global window $\mathrm{U}$-value is 2.83 $\mathrm{W} /\left(\mathrm{m}^{2} \mathrm{~K}\right)$, while the Solar Heat Gain Coefficient is 0.49 . $\mathrm{U}$-value for vertical surfaces is $0.40 \mathrm{~W} /\left(\mathrm{m}^{2} \mathrm{~K}\right), 0.32$ $\mathrm{W} /\left(\mathrm{m}^{2} \mathrm{~K}\right)$ for the roof and $0.42 \mathrm{~W} /\left(\mathrm{m}^{2} \mathrm{~K}\right)$ for the floor. All walls have an internal mass layer (brick, $30 \mathrm{~cm}$ for external walls) and external insulation ( $5 \mathrm{~cm}$ for the walls and $9 \mathrm{~cm}$ for the roof).

Thermal internal loads are caused by lighting and office equipment. Lighting power installed is $5 \mathrm{~W} / \mathrm{m}^{2}$, controlled by an illuminance dimmering with a setpoint of 500 lux activated by the presence of people inside the building. 
Other electrical loads are included: computers with monitors and a printer, overall $30 \mathrm{~W} / \mathrm{m}^{2}$ installed (BRECSU, 2000; CIBSE, 2012).

Natural ventilation is modelled through the separate contributions of wind and stack to the airflow through the Wind and stack empiric formulation (American Society of Heating \& Air-Conditioning, 2005; Guarino et al., 2016): wind induced ventilation is obtainable through equation (6), while the equation (7) is used for calculating the ventilation rate due to stack effect:

$$
\begin{gathered}
Q_{w}=C_{O} A_{\text {opening }} W_{S} \\
Q_{S}=C_{D} A_{\text {opening }} \sqrt{2 g \Delta H_{N P L}\left(\left|T_{Z}-T_{O}\right| / T_{O}\right.}
\end{gathered}
$$

Where $\mathrm{C}_{O}$ is the opening effectiveness, $\mathrm{A}$ is the opening area $\left[\mathrm{m}^{2}\right], \mathrm{W}_{\mathrm{S}}$ is the wind speed, $\mathrm{C}_{\mathrm{D}}$ is the Discharge coefficient for opening, $\Delta \mathrm{H}_{\mathrm{NPL}}$ is the height from midpoint of lower opening to the neutral pressure level $[\mathrm{m}], \mathrm{T}_{\mathrm{Z}}$ and $\mathrm{T}_{\mathrm{O}}$ are respectively the temperature of the zone and the outdoor one $\left[{ }^{\circ} \mathrm{C}\right]$. Windows are open when external air temperature is in the range of $18<\mathrm{T}_{\mathrm{O}}<26^{\circ} \mathrm{C}$, internal temperature is below $23^{\circ} \mathrm{C}$ and wind speed is lower than $2 \mathrm{~m} / \mathrm{s}$.

Finally, to cover the heating and cooling demand an ideal loads air systems using $20^{\circ} \mathrm{C}$ and $26^{\circ} \mathrm{C}$ as heating and cooling set-points was used, with a coefficient of performance and an energy efficiency ratio of around 3.2 and 3, respectively. This choice is based on the difficulty to quantify potential energy efficiency improvements in HVAC systems up to 2099 and to be able to perform a solid comparison between all results in all scenarios.

\section{Results}

In this section, based on the assumptions made in the previous section and based on the assumptions of the latest IPCC future climate projections, results on the future climate projections and the potential impact of climate change on the energy uses for heating and cooling for the city of Palermo are presented.

\section{Results on future climate projections}

Figure 3 shows the yearly mean dry bulb temperature for the future period 2020-2099 in the case of RCP4.5 and RCP8.5 scenarios.

For both scenarios, the yearly mean dry-bulb temperature is expected to increase. In particular, considering the RCP4.5 scenario for the year 2099, the results show that the yearly temperature increase is expected to be between $2.4^{\circ} \mathrm{C}$ (ACCESS1.3) and $3.3^{\circ} \mathrm{C}$ (HadGEM2-CC) compared to the mean yearly temperature of the current situation $\left(18.8^{\circ} \mathrm{C}\right)$. On the other hand, the results for the year 2099 under the scenario RCP8.5 show that the model ACCESS1.3 is the model that foresees the greatest increase in yearly temperature $\left(+5^{\circ} \mathrm{C}\right)$ while the HadGEM2-AO is characterized by the lowest increase for the city of Palermo $\left(+4.5^{\circ} \mathrm{C}\right)$.

The distribution of the results among the five GCMs shows some differences between the models. Considering the scenario RCP4.5 (Figure 3a), the model ACCESS 1.3 proposes the most extreme weather forecasts (for about
$50 \%$ of the time in the period between 2020 and 2099, this model shows the highest mean annual temperatures), while the model ACCESS 1.0 shows the most temperate one. The results for the scenario RCP8.5 (Figure 3b) show that the model HadGEM2-AO foresees the greatest increase in yearly temperature (for about $46 \%$ of the time in the future period considered, this model shows the higher mean yearly temperatures if compared to the other GCMs). Finally, for both scenarios, the Data fusion model always shows intermediate results between all models investigated.

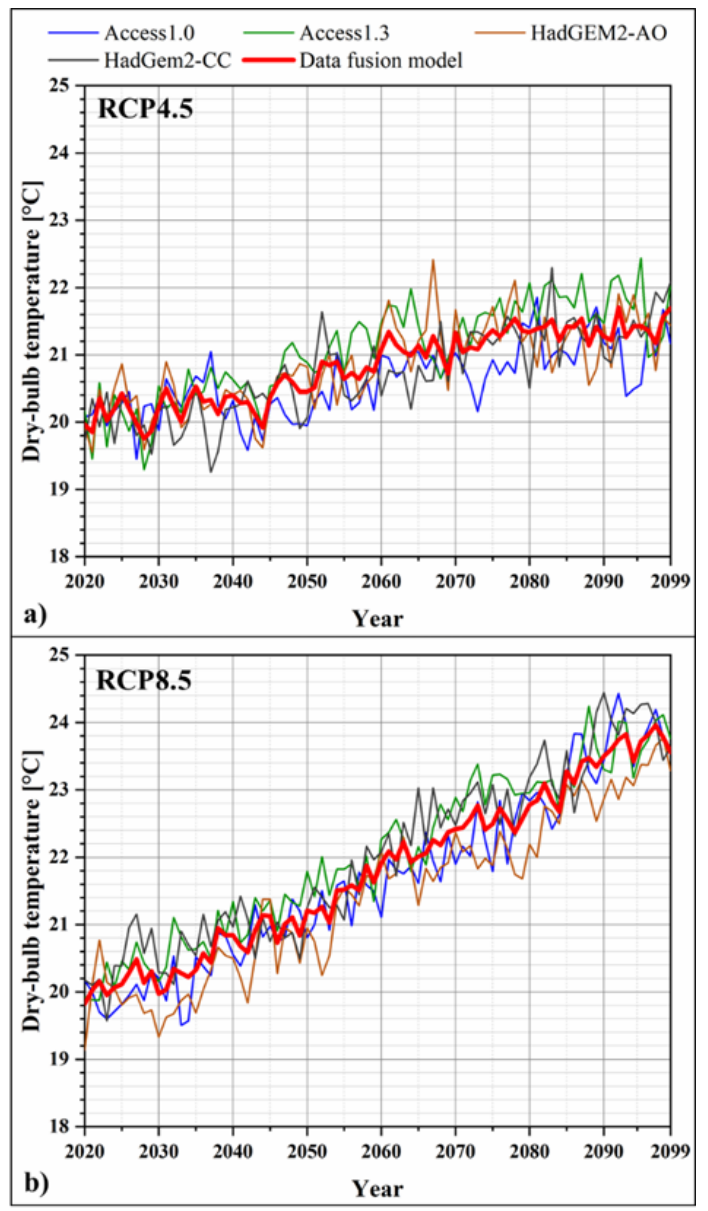

Figure 3: Future yearly average values of dry-bulb temperature under the RCP4.5 and RCP8.5 scenarios.

\section{Results of building simulation}

The case study was simulated for the current situation (i.e. the energy simulation was run using the IWEC weather file for the city of Palermo, that covers the period 19821999) and for the two different future scenarios, each with all climate data models mentioned in the previous sections as well as with the Data fusion model.

Table 6 shows the monthly electricity energy demand for heating and cooling for the current situation. Due to a mild climate, high internal thermal loads and large glazed facades, the yearly heating energy demand (around 5.5 $\mathrm{kWh}_{\mathrm{e}} /\left(\mathrm{m}^{2} \mathrm{year}\right)$ ) is lower than the cooling demand (about $\left.13.5 \mathrm{kWh}_{\mathrm{e}} /\left(\mathrm{m}^{2} \mathrm{year}\right)\right)$. In detail, the months that need more heating are January $\left(1.8 \mathrm{kWh} / \mathrm{m}^{2}\right)$ and February (1.6 $\mathrm{kWh}_{\mathrm{e}} / \mathrm{m}^{2}$ ), while the months of July and August require 
the highest cooling demand, respectively $4.4 \mathrm{kWh} / \mathrm{m}^{2}$ and $5.5 \mathrm{kWh} / \mathrm{m}^{2}$.

Table 6: Heating and cooling energy demand for the current situation.

\begin{tabular}{|l|c|c|}
\hline & $\begin{array}{c}\text { Heating energy demand } \\
{\left[\mathbf{k W h} / \mathbf{m}^{\mathbf{2}}\right]}\end{array}$ & $\begin{array}{c}\text { Cooling energy demand } \\
{\left[\mathbf{k W h} \mathbf{h} \mathbf{m}^{\mathbf{2}}\right]}\end{array}$ \\
\hline Jan & 1.75 & 0 \\
\hline Feb & 1.64 & 0 \\
\hline Mar & 0.54 & 0 \\
\hline Apr & 0.13 & 0.07 \\
\hline May & 0 & 0.18 \\
\hline Jun & 0 & 1.29 \\
\hline Jul & 0 & 4.35 \\
\hline Aug & 0 & 5.47 \\
\hline Sep & 0 & 1.51 \\
\hline Oct & 0 & 0.64 \\
\hline Nov & 0.23 & 0.02 \\
\hline Dec & 1.21 & 0 \\
\hline Tot & 5.50 & 13.53 \\
\hline
\end{tabular}

Figure 4 shows the yearly electricity energy demand for cooling and heating for the future forecast period 20202099 in the two RCP scenarios. Rises in the yearly cooling energy use and decrease in heating energy use are found due to the outdoor dry-bulb temperature increase brought by the climate change, but the magnitude of the change varies for different climate change scenarios.

Although in the current situation, the heating energy demand accounts for roughly the $30 \%$ of the total energy uses for air conditioning, this is not the case anymore for the future scenarios. For example, considering the future projection for the year 2099, the cooling energy demand is nearly increased by $50 \%$ in the RCP 4.5 scenario whereas the heating energy demand (Figure 4c) is reduced to a third. On the other hand, in the RCP8.5 scenario the heating energy demand (Figure $4 \mathrm{~b}$ ) is close to zero while the cooling energy demand (Figure 4d) is increased threefold.

As per the previous results on the future climate projections, also the results on the cooling and heating energy demand are very sensitive to choice of the GCM.

In detail, the results on the heating energy demand show highest differences among the models, while considering the cooling energy demand, for both scenarios the results are more uniform between the different models. For example, considering the cooling energy demand for the scenario RCP4.5, results can vary as much as $35 \%$ (year 2095) whit a mean variation in the period 2020-2099 of about $17 \%$, merely by using one data source to another.

In this context, the Data fusion model (red bold line in Figure 4) always shows middle results between all GCMs investigated.

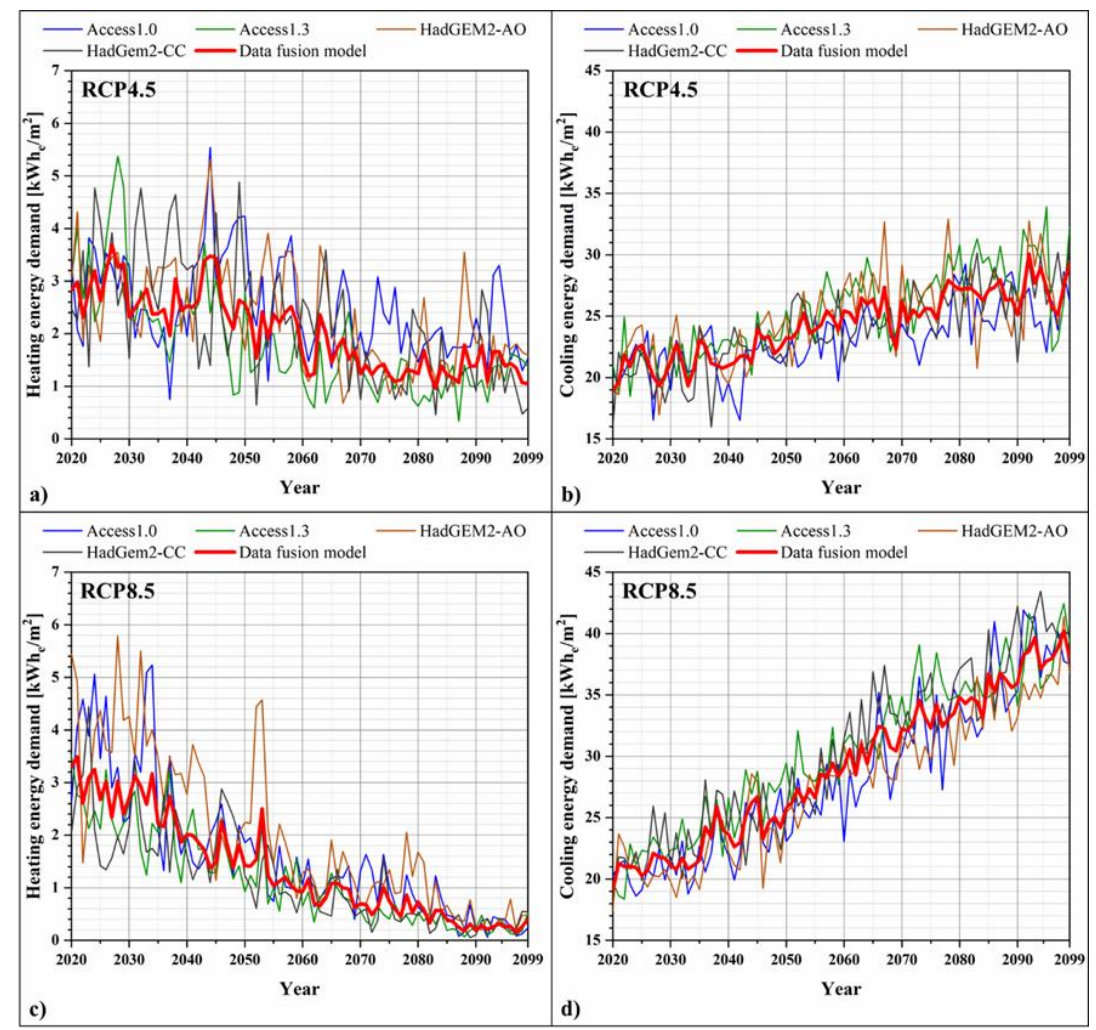

Figure 4: Future heating and cooling energy demand under the RCP4.5 and RCP8.5 scenarios.

\section{Discussions and conclusions}

A range of uncertainties linked to predicted energy demand changes for buildings under projected future weathers is due to the availability of different climate models used, reinforcing the need for careful assessment of the available GCMs for any specific location when 
developing specific building designs. In this context, the paper proposes the analysis of four different climate models approved from the IPCC, showing a wide variability among the future climate forecast of the different models. Within two RCP scenario (RCP4.5 and RCP8.5), results from a climate analysis indicate that this range can have a large impact on the predicted energy consumption of the building sector.

For example, considering the cooling energy demand for the scenario RCP8.5, by using data from one climate model rather than another, results can vary as much as $31 \%$ (year 2046), while considering the scenario RCP4.5 the maximum variation in the cooling energy requirements is equal to about $35 \%$ (year 2095). Therefore, so large variations in predicting the future energy demands of the building sector could relevant impacts in terms of costs, decarbonisation potential and environmental impacts of this sector.

In this context, this research presented a methodology to integrate different climate change models data into a new 'data-fusion' model, in order to achieve a new more robust dataset if compared to the real available data.

The approach presented in this paper can help local decision makers and local utilities make more informed decisions regarding future policies and business choices. The paper is also aimed towards buildings designers and practitioners of non steady-state building simulation, since the evolution of predicting weather data for the next decades is one of the research challenges of the years to come and one to impact the building modelling and simulation in the next decades.

The same process can be applied to other locations throughout the world, which can help in making informed decisions regarding building standards, energy management and emission policies.

Furthermore, the generation of building simulation weather files allowed for the quantification of potential significant differences between different models outputs, strengthening the need for a more detailed approach to climate change modelling.

Finally, the research also presented the usage of climatechanged weather data by performing an energy analysis based on building simulation suggesting that future global warming will have a significant impact on building energy performances. In detail, the results show, in both RCP scenarios considered, consistent and large increases in future air temperature. In this context, in order to try and avoid potentially much larger issues in the future, there is a need for tools and methods that allow to include climate change as one of the variables to be taken into consideration during the design stage for both the construction of the new buildings and the retrofit of the existing stock.

\section{References}

Allen, M. R., Barros, V. R., Broome, J., Cramer, W., Christ, R., Church, J. A., ... Dubash, N. K. (2014). IPCC fifth assessment synthesis report-climate change 2014 synthesis report.
American Society of Heating, R., \& Air-Conditioning, E. (2005). 2005 ASHRAE Handbook: Fundamentals SI edition. Atlanta, Ga.: American Society of Heating Refrigerating and Air-Conditionin.

Artmann, N., Gyalistras, D., Manz, H., \& Heiselberg, P. (2008). Impact of climate warming on passive night cooling potential. Building Research \& Information, 36(2), 111-128.

Beccali, M., Cellura, M., Finocchiaro, P., Guarino, F., Longo, S., \& Nocke, B. (2012). Life Cycle Assessment performance comparison of small solar thermal cooling systems with conventional plants assisted with photovoltaics. In Energy Procedia (Vol. 30, pp. 893-903).

Beccali, M., Cellura, M., Longo, S., \& Guarino, F. (2016). Solar heating and cooling systems versus conventional systems assisted by photovoltaic: Application of a simplified LCA tool. Solar Energy Materials and Solar Cells, 156, 92-100.

Beccali, M., Cellura, M., \& Mistretta, M. (2007). Environmental effects of energy policy in sicily: The role of renewable energy. Renewable and Sustainable Energy Reviews, 11(2), 282-298.

Belcher, S. E., Hacker, J. N., \& Powell, D. S. (2005). Constructing design weather data for future climates. Building Services Engineering Research and Technology, 26(1), 49-61.

Bobba, S., Mathieux, F., Ardente, F., Blengini, G. A., Cusenza, M. A., Podias, A., \& Pfrang, A. (2018). Life Cycle Assessment of repurposed electric vehicle batteries: an adapted method based on modelling energy flows. Journal of Energy Storage, 19, 213-225.

Bojanowski, J. S., Vrieling, A., \& Skidmore, A. K. (2014). A comparison of data sources for creating a long-term time series of daily gridded solar radiation for Europe. Solar Energy, 99, 152-171.

Brands, S., Herrera, S., Fernández, J., \& Gutiérrez, J. M. (2013). How well do CMIP5 Earth System Models simulate present climate conditions in Europe and Africa? Climate Dynamics, 41(3), 803-817.

BRECSU (2000). Energy Consumption Guide 19, Energy use in offices. Watford. Retrieved from www.cibse.org/getmedia/7fb5616f-1ed7-4854-bf722dae1d8bde62/ECG19-Energy-Use-in-Offices(formerly-ECON19

Carvalho, D., Rocha, A., Gómez-Gesteira, M., \& Silva Santos, C. (2017). Potential impacts of climate change on European wind energy resource under the CMIP5 future climate projections. Renewable Energy, 101, 29-40.

Cellura, M., Campanella, L., Ciulla, G., Guarino, F., Lo Brano, V., Cesarini, D. N., \& Orioli, A. (2011). The redesign of an Italian building to reach net zero energy performances: A case study of the SHC Task 40 ECBCS Annex 52. In ASHRAE Annual Conference (PART 2, Vol. 117, pp. 331-339). 
Cellura, M., Guarino, F., Longo, S., \& Mistretta, M. (2017). Modeling the energy and environmental life cycle of buildings: A co-simulation approach. Renewable and Sustainable Energy Reviews, 80, 733 742.

Cellura, M., Guarino, F., Longo, S., \& Tumminia, G. (2018). Climate change and the building sector: Modelling and energy implications to an office building in southern Europe. Energy for Sustainable Development, 45, 46-65.

CIBSE (2012). Cibse Guide F: Energy efficiency in buildings. London.

Dee, D. P., Uppala, S. M., Simmons, A. J., Berrisford, P., Poli, P., Kobayashi, S., Vitart, F. (2011). The ERAInterim reanalysis: Configuration and performance of the data assimilation system. Quarterly Journal of the Royal Meteorological Society, 137(656), 553-597.

DoE, U. S. (2010). Energyplus engineering reference. The Reference to Energyplus Calculations.

Ferrari, S., \& Zagarella, F. (2015). Costs assessment for building renovation cost-optimal analysis. In P. M. \& C. V. (Eds.), 6th International Building Physics Conference, IBPC 2015 (Vol. 78, pp. 2378-2384).

Ferrari, S., \& Zanotto, V. (2012). Office Buildings Cooling Need in the Italian Climatic Context: Assessing the Performances of Typical Envelopes. Energy Procedia, 30, 1099-1109.

Ferrari, S., \& Zanotto, V. (2016). Defining representative building energy models. (B. E., F. M., \& S. M., Eds.), SpringerBriefs in Applied Sciences and Technology. Springer Verlag.

Finocchiaro, P., Beccali, M., Cellura, M., Guarino, F., \& Longo, S. (2016). Life Cycle Assessment of a compact Desiccant Evaporative Cooling system: The case study of the "Freescoo." Solar Energy Materials and Solar Cells, 156, 83-91.

Goia, F. (2016). Search for the optimal window-to-wall ratio in office buildings in different European climates and the implications on total energy saving potential. Solar Energy, 132, 467-492.

Guan, L. (2012). Energy use, indoor temperature and possible adaptation strategies for air-conditioned office buildings in face of global warming. Building and Environment, 55, 8-19.

Guarino, F., Tumminia, G., Longo, S., Mistretta, M., Bilotta, R., \& Cellura, M. (2016). Energy planning methodology of net-zero energy solar neighborhoods in the Mediterranean basin. Science and Technology for the Built Environment, 22(7), 928-938.

Gupta, R., \& Gregg, M. (2012). Using UK climate change projections to adapt existing English homes for a warming climate. Building and Environment, 55, 2042.

Hamdy, M., Carlucci, S., Hoes, P.-J., \& Hensen, J. L. M. (2017). The impact of climate change on the overheating risk in dwellings-A Dutch case study.
Building and Environment, 122(Supplement C), 307323.

Ministero dello Sviluppo Economico. (2015). Decreto interministeriale 26 giugno 2015 - Applicazione delle metodologie di calcolo delle prestazioni energetiche e definizione delle prescrizioni e dei requisiti minimi degli edifici. Gazzetta Ufficiale della Repubblica italiana 2015

Pedregosa, F., Varoquaux, G., Gramfort, A., Michel, V., Thirion, B., Grisel, O., ... Dubourg, V. (2011). Scikitlearn: Machine learning in Python. Journal of Machine Learning Research, 12(Oct), 2825-2830.

Ren, Z., Chen, Z., \& Wang, X. (2011). Climate change adaptation pathways for Australian residential buildings. Building and Environment, 46(11), 23982412.

Robert, A., \& Kummert, M. (2012). Designing net-zero energy buildings for the future climate, not for the past. Building and Environment, 55, 150-158.

Song, X., \& Ye, C. (2017). Climate Change Adaptation Pathways for Residential Buildings in Southern China. Energy Procedia, 105(Supplement C), 3062 3067.

Stocker D. Qin, G., K. Plattner, M. Tignor, S.K. Allen, J. Boschung, A. Nauels, Y. Xia, V. Bex and P.M. Midgley (eds.), T. F. (2013). IPCC, Climate Change 2013: The Physical Science Basis. Contribution of Working Group I to the Fifth Assessment Report of the Intergovernmental Panel on Climate Change.

Taylor, K. E., Stouffer, R. J., \& Meehl, G. A. (2012). An overview of CMIP5 and the experiment design. Bulletin of the American Meteorological Society, 93(4), 485-498.

Thevenard, D. J., \& Brunger, A. P. (2002). The development of typical weather years for international locations: part I, algorithms. ASHRAE Transactions, $108,376$.

Tumminia, G., Guarino, F., Longo, S., Ferraro, M., Cellura, M., \& Antonucci, V. (2018). Life cycle energy performances and environmental impacts of a prefabricated building module. Renewable and Sustainable Energy Reviews, 92, 272-283.

Wang, H., \& Chen, Q. (2014). Impact of climate change heating and cooling energy use in buildings in the United States. Energy and Buildings, 82, 428-436.

Wang, L., Liu, X., \& Brown, H. (2017). Prediction of the impacts of climate change on energy consumption for a medium-size office building with two climate models. Energy and Buildings, 157(Supplement C), 218-226.

Zhai, Z. J., \& Helman, J. M. (2019). Implications of climate changes to building energy and design. Sustainable Cities and Society, 44, 511-519.

Zou, H., \& Hastie, T. (2005). Regularization and variable selection via the elastic net. Journal of the Royal Statistical Society: Series B (Statistical Methodology), 67(2), 301-320. 